\title{
Two new coprophilous varieties of Panaeolus (Psathyrellaceae, Agaricales) from Punjab, India
}

\author{
Amandeep $\mathrm{K}^{1^{*}}$, Atri $\mathrm{NS}^{2}$ and Munruchi $\mathrm{K}^{2}$ \\ ${ }^{1}$ Desh Bhagat College of Education, Bardwal-Dhuri-148024, Punjab, India. \\ ${ }^{2}$ Department of Botany, Faculty of Life Sciences, Punjabi University, Patiala-147002, Punjab, India.
}

Amandeep K, Atri NS and Munruchi K 2013 - Two new coprophilous varieties of Panaeolus (Psathyrellaceae, Agaricales) from Punjab, India. Mycosphere 4(3), 616-625, Doi 10.5943/mycosphere/4/3/13

\begin{abstract}
Two new coprophilous varieties of Panaeolus are described from Punjab, India. $P$. africanus var. diversistipus var. nov. was found growing solitary on a cattle dung heap from Hoshiarpur district and P. speciosus var. pilocystidiosus var. nov. was growing scattered on cattle dung from Barnala district. The new taxa are described along with habitat photographs and line drawings of macroscopic and microscopic features and their distinctive features are discussed.
\end{abstract}

Key Words - Coprophilous - India - Panaeolus - Psathyrellaceae - Punjab

\section{Introduction}

The genus Panaeolus (Fr.) Quél. is characterized by small to medium sized carpophores with usually coprophilous habitat; often bluing when bruised or with age; adnexed to adnate, variegated, greyish-black lamellae; epithelial pileus cuticle and reddish brown to blackish brown spores which do not fade in concentrated sulphuric acid. The members of the closely related genus Psathyrella (Fr.) Quél. are usually found growing on wood or lignin-enriched soils, have brittle white stipe and their basidiospores loose color in concentrated sulphuric acid. The gills of Panaeolus do not deliquesce as do those of the related genera Coprinopsis P. Karst., Coprinellus P. Karst. and Parasola Redhead, Vilgalys \& Hopple. The genus Panaeolina Maire is distinguished by having ornamented spores and dark brown gills, in comparison to smooth basidiospores and mottled greyish-black gills in Panaeolus.

Fifteen species of Panaeolus are reported by Kirk et al. (2008). However, MycoBank mentions 150 legitimate species of this genus. From India 22 species are already known (Abraham 1991, Bhavani Devi 1995, Bhide et al. 1987, Bose 1920, Dhancholia et al. 1991, Ghosh et al. 1967, Lakhanpal 1986, 1993, 1995, Manimohan et al. 2007, Natarajan \& Raaman 1983, 1984, Pathak \& Ghosh 1962, Patil et al. 1995, Sarbhoy \& Daniel 1981, Sathe \& Sasangan 1977, Vrinda et al. 1999). During surveys conducted in various localities of Punjab in North India, two new coprophilous fungi $P$. africanus var. diversistipus and $P$. speciosus var. pilocystidiosus were found and are described in this paper.

\section{Material and methods}

The materials were collected from dung in Punjab. The standard methods of collection, 
preservation and description of agarics were followed using the terminology by Atri et al. (2005). The colour terminology used for macroscopic description is that of Kornerup \& Wanscher (1978). The specimens were hot air dried and preserved in cellophane bags containing 1-4 dichlorobenzene. The microscopic characters were observed by cutting free-hand sections after reviving a part of the dried specimens in $10 \% \mathrm{KOH}$ solution. Line drawings of microscopic details were drawn with the aid of a camera lucida under an oil lens. The specimens have been deposited in the Herbarium of Botany Department, Punjabi University, Patiala (Punjab), India under PUN (Holmgren \& Keuken 1974).

\section{Taxonomic descriptions}

Panaeolus africanus var. diversistipus Amandeep Kaur, NS Atri \& Munruchi Kaur var. nov.

MycoBank - MB 803831

Figs. 1-2

Etymology - named for its diverse coloured stipe.

Carpophore $5.4 \mathrm{~cm}$ in height. Pileus $1.8 \mathrm{~cm}$ broad, $1.3 \mathrm{~cm}$ high, convex; surface dry, yellowish white $\left(2 \mathrm{~A}_{2}\right)$ with greyish shades, rugulose; margin regular, not splitting at maturity, nonstriate, appendiculate, with brownish grey $\left(6 \mathrm{D}_{2}\right)$ marginal band; cuticle not peeling; flesh thin, bluing when handled, non-deliquescent; taste and odour not distinctive. Lamellae adnexed, unequal, 3-sized, subdistant, moderately broad, up to $0.4 \mathrm{~cm}$, fragile, greyish-black; gill edges serrate, white. Spore print black. Stipe central, $5.2 \mathrm{~cm}$ long, $0.2 \mathrm{~cm}$ broad, tubular, equal in diameter throughout, hollow, surface white $\left(2 \mathrm{~A}_{1}\right)$ at the apex, greyish brown $\left(6 \mathrm{~F}_{3}\right)$ at the central part, light brown $\left(6 \mathrm{D}_{4}\right)$ at the base, with white scales throughout the surface, white cottony basal mycelium present, exannulate.

Basidiospores $12-14.5 \times 8.5-10.2 \mu \mathrm{m}(\mathrm{Q}=1.41)$, limoniform in face view, ellipsoidal in side view, with a broad truncate germ pore, thick-walled, smooth, blackish brown, not bleaching in concentrated $\mathrm{H}_{2} \mathrm{SO}_{4}$. Basidia 18.7-23.8 $\times$ 9.3-12 $\mu \mathrm{m}$, clavate, 4-spored, thin-walled, weakly granular; sterigmata 3.4-4.3 $\mu \mathrm{m}$ long. Gill edges sterile. Cheilocystidia $22-34 \times 6.8-12 \mu \mathrm{m}$, abundant, lageniform or ventricose fusoid, thin-walled, granular, some with densely granular tips. Pleurocystidia chrysocystidioid, 44-63 $\times 15.3-20.3 \mu \mathrm{m}$, metulloidal, ventricose fusoid, thick walled, granular, with golden contents, some with apical encrustations. Pileus cuticle cellular with scattered pileocystidia, cellular elements globose to subglobose, thin-walled, hyaline, 3.4-15.3 $\mu \mathrm{m}$ broad; pileocystidia $23.8-35.7 \times 6.8-10 \mu \mathrm{m}$, few, scattered, cylindrical or clavate, thin-walled, granular; context made up of interwoven, thin-walled 3.4-15.3 $\mu \mathrm{m}$ broad hyphae. Hymenophoral trama regular, composed of thin-walled 6.8-12 $\mu \mathrm{m}$ broad hyphae. Stipe cuticle hyphal, with caulocystidia scattered in groups, context hyphae longitudinally parallel, loosely arranged, thinwalled, hyaline $8.5-22 \mu \mathrm{m}$ broad, caulocystidia $25.5-34 \times 8.5-12.7 \mu \mathrm{m}$, cylindrical to clavate, thinwalled, granular, some with densely granular tips. Clamp connections absent throughout.

Material examined - India, Punjab, Hoshiarpur (295 m): Jejon Duaba, growing solitary on mixed cattle dung heap, 5 July, 2011, Amandeep Kaur, PUN 4342 (Holotype).

Remarks - The macroscopic and microscopic details of the above examined collection are similar to those given for $P$. africanus by Stamets (1996) except for the stipe characteristics. Stamets (1996) described the stipe surface of $P$. africanus as whitish having pinkish shades with pruinose apex. However, in the present collection the stipe surface is white towards the apex, without any pinkish tone, greyish brown in the middle and light brown towards the base, and is covered with white scales throughout and white cottony mycelium is present at the base. To accommodate this differently coloured stipe variant of $P$. africanus, a new variety, is proposed. 


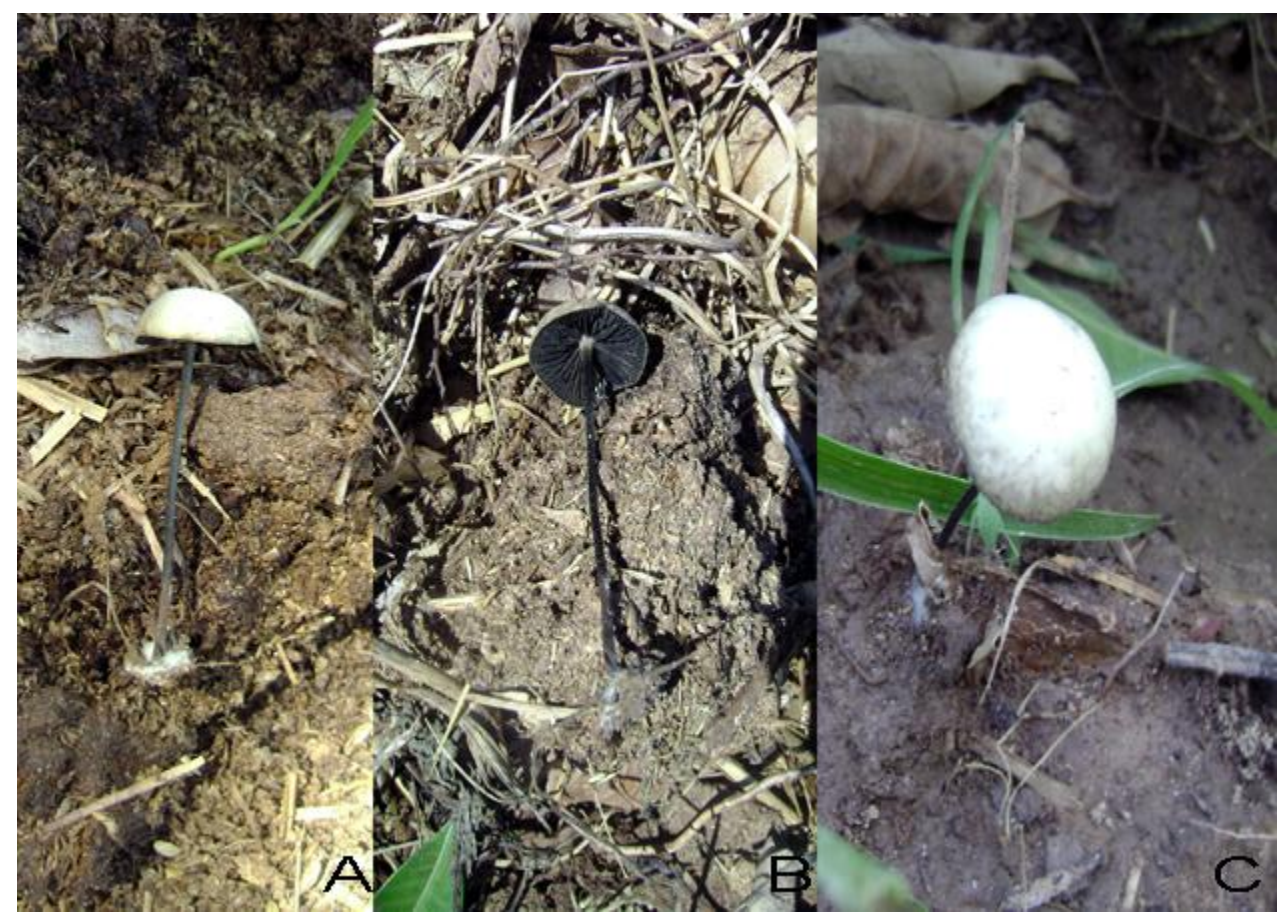

Fig. 1 - Panaeolus africanus var. diversistipus. A Carpophore growing in natural habitat B Carpophore showing diverse coloured stipe C Rugulose pileal surface.

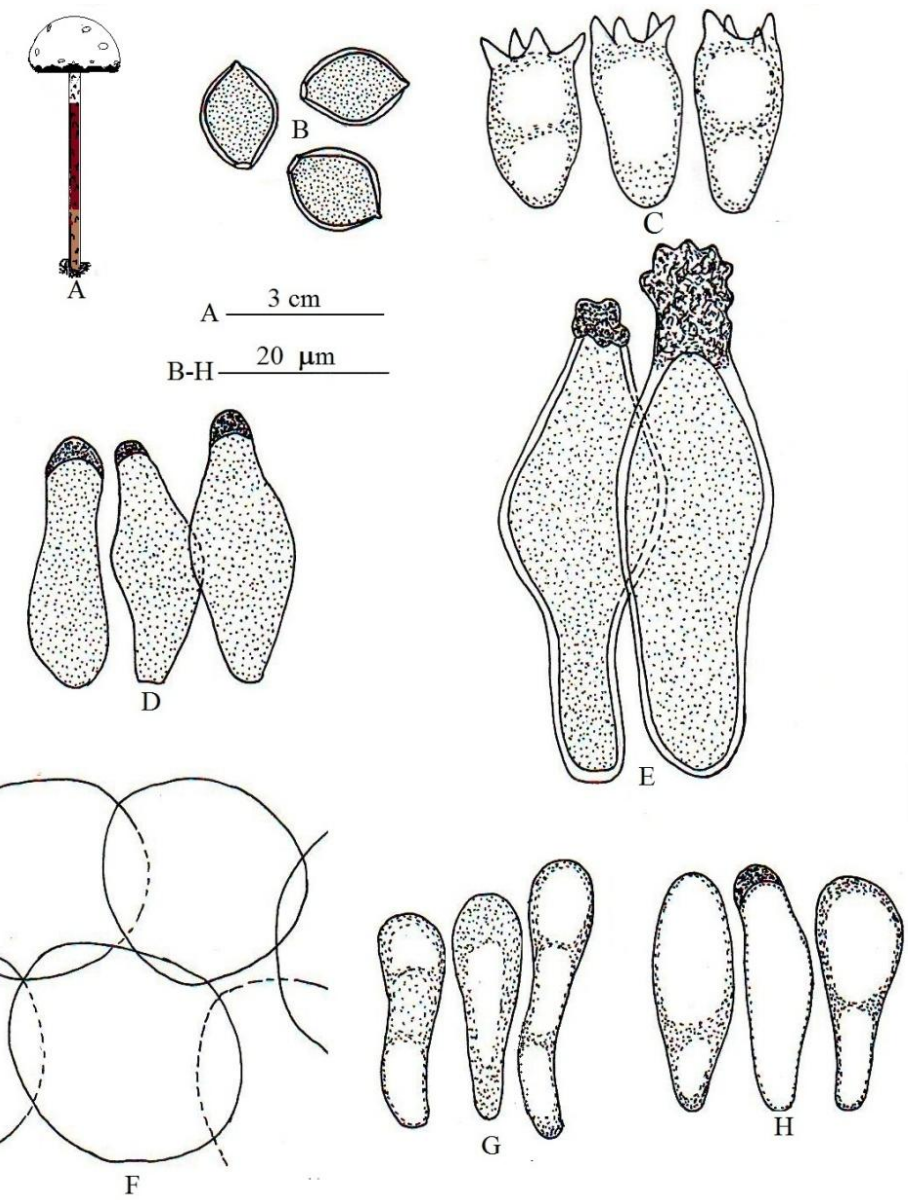

Fig. 2 - Panaeolus africanus var. diversistipus. A Carpophore B Basidiospores C Basidia D Cheilocystidia E Chrysocystidia F Pileus cuticle elements G Pileocystidia H Caulocystidia. 
Stamets (1996) reported the species as coprophilous in habitat growing on hippopotamus and elephant dung from Central and South Africa in the spring and rainy seasons. Earlier this species was collected growing in groups on elephant dung in the month of December from South India (Natarajan \& Raaman, 1983, 1984). Presently, the collection has been made from mixed dung heap from North India.

Panaeolus speciosus var. pilocystidiosus Amandeep Kaur, NS Atri \& Munruchi Kaur var. nov.

Figs 3-4

MycoBank - MB 803838

Etymology - referring to the presence of pileocystidia

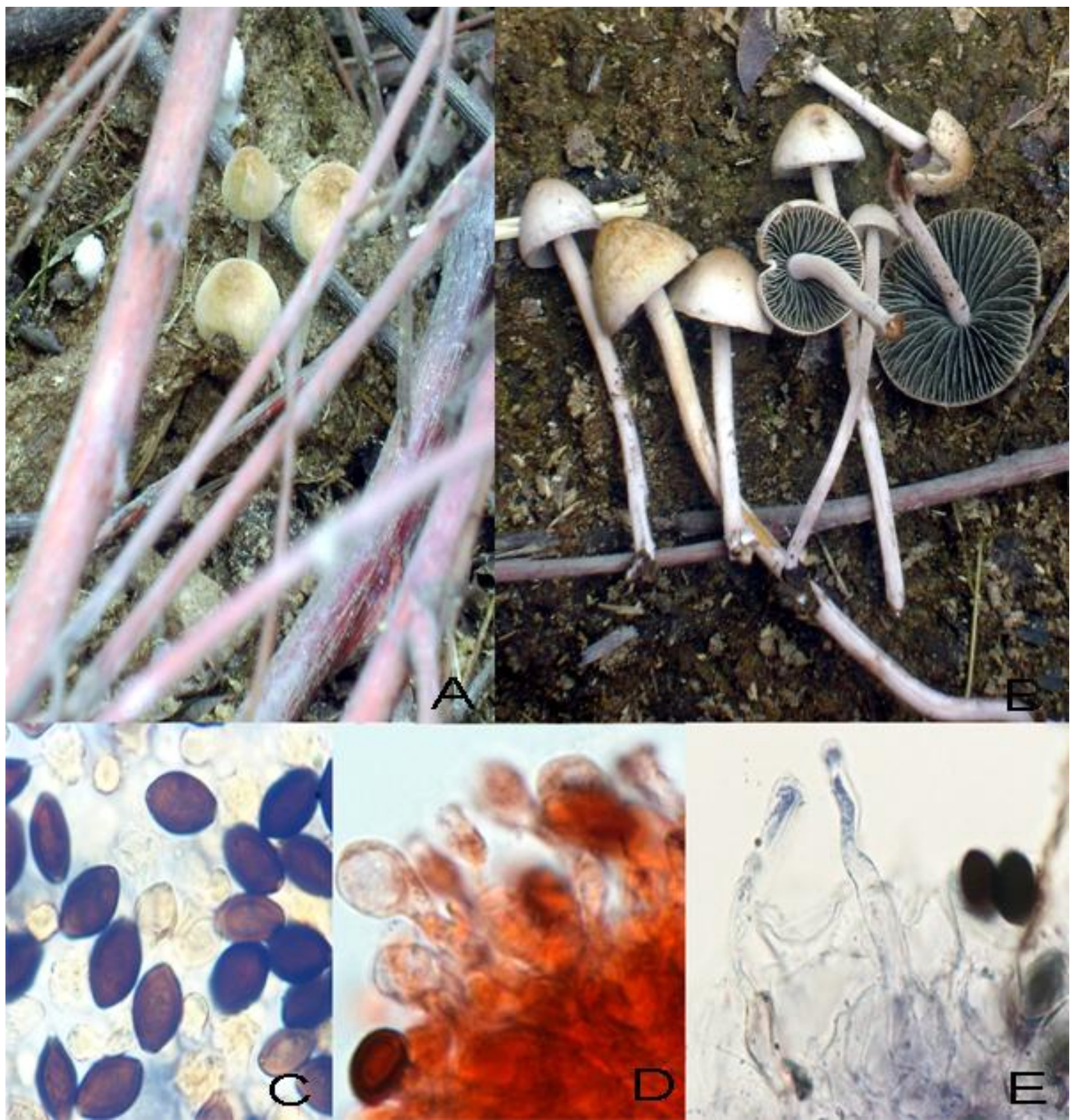

Fig. 3 - Panaeolus speciosus var. pilocystidiosus. A Carpophores growing in natural habitat B Carpophores showing yellowish white stipe bruising greyish brown C Basidiospores D Cheilocystidia E. Pileocystidia F Caulocystidia. 

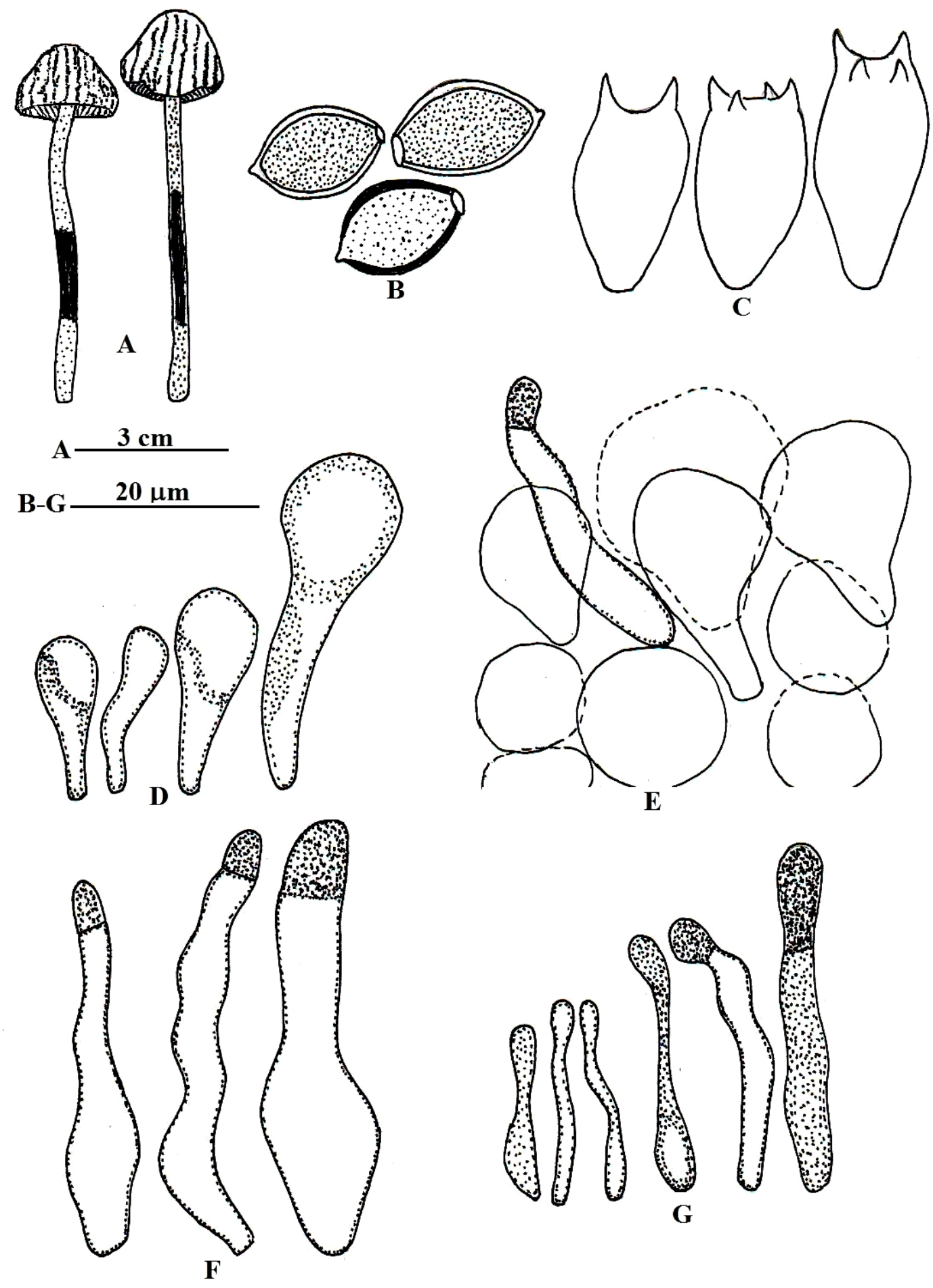

Fig. 4 - Panaeolus speciosus var. pilocystidiosus. A Carpophores B Basidiospores C Basidia D Cheilocystidia E. Pileal elements F Pileocystidia G Caulocystidia.

Carpophores $3.5-8.1 \mathrm{~cm}$ in height; Pileus $2-2.5 \mathrm{~cm}$ broad, $1.5-1.8 \mathrm{~cm}$ high, conical to convex; surface yellowish $\left(2 \mathrm{~A}_{8}\right)$ with orange $\left(6 \mathrm{~A}_{8}\right)$ scales, hygrophanous, fading to pale yellow on drying; margin regular, not splitting at maturity, non-striate; flesh thin, pale, unchanging; cuticle fully peeling; taste mild; odour farinaceous. Lamellae adnate, unequal, 3-sized, subdistant, ventricose, moderately broad, up to $0.4 \mathrm{~cm}$ broad, fragile, greyish-black; gill edges smooth, white. 
Spore print greyish black. Stipe 3.3-7.8 cm long, 0.2-0.25 cm broad, cylindrical, equal in diameter throughout, solid when young, hollow at maturity, surface yellowish white, changing to greyish brown when bruised, pruinose; annulus absent.

Basidiospores $12.8-15.5 \times 8.5-10 \mu \mathrm{m}(\mathrm{Q}=1.52)$, lenticular, limoniform in face view, ellipsoidal in side view, with a broad central germ pore, thick-walled, smooth, chocolate-brown, not bleaching in concentrated $\mathrm{H}_{2} \mathrm{SO}_{4}$. Basidia 14-24 $\times 8.4-11.4 \mu \mathrm{m}$, clavate, (2-), 4-spored, thinwalled, hyaline; sterigmata $2.8-4.3 \mu \mathrm{m}$ long. Gill edges sterile. Cheilocystidia 15.6-28.3 × 4.3-12.6 $\mu \mathrm{m}$, crowded, pedicellate clavate with round apex, thin-walled, hyaline. Pleurocystidia absent. Pileus cuticle cellular with scattered pileocystidia; cellular elements $14-25.5 \times 11.5-18.5 \mu \mathrm{m}$, sphaeropedunculate to pedicellate clavate, thin-walled, hyaline; pileocystidia $25.5-45.5 \times 4.4-18.4$ $\mu \mathrm{m}$, polymorphic, elongated fibrillose, wavy, cylindrical, lageniform, ventricose-fusoid, thinwalled, with granular tips; pileus context homoiomerous, made up of parallel, septate, $2.8-7 \mu \mathrm{m}$ broad hyphae. Hymenophoral trama regular, composed of thin-walled, hyaline $2.8-8.5 \mu \mathrm{m}$ broad hyphae. Subhymenium pseudoparenchymatous. Stipe cuticle hyphal with abundant caulocystidia all over the surface; context made up of longitudinally running, cylindrical, thin-walled 3-14 $\mu \mathrm{m}$ broad hyphae; caulocystidia $15.5-42.5 \times 2-6 \mu \mathrm{m}$, polymorphic, wavy, fibrillose, cylindrical to lageniform, thin-walled, granular, sometimes with long neck and subcapitate densely granular tips. Clamp connections absent throughout.

Material examined - India, Punjab, Barnala $(228 \mathrm{~m})$ : Rarh, growing scattered on cattle dung, 26 June, 2008, Amandeep Kaur, PUN 4081 (Holotype).

Remarks - The diagnostic characters of the Indian collection are in agreement to those given for P. speciosus growing on horse dung from Scotland (Watling \& Gregory 1987). However, the basidiospores of the Scottish collection range from 14-20 $\times 10-12 \mu \mathrm{m}$ in size as compared to $12.8-15.5 \times 8.5-10 \mu \mathrm{m}$ in the present collection. In the Scotland collection, clamp connections are reported while pileocystidia are reported to be absent (Watling \& Gregory 1987). In the Indian material, clamp connections are absent while pileocystidia are present on the pileus cuticle. In view of these sharp differences, $P$. speciosus var. pilocystidiosus is proposed as a new variety. The species is reported for the first time from India.

\section{Acknowledgements}

Authors acknowledge the grant-in-aid under SAP-III programme by University Grants Commission to the Department of Botany, Punjabi University, Patiala, Punjab of which Mycology and Plant Pathology is one of the thrust areas.

\section{References}

Abraham SP 1991 - Kashmir fungal floralan overview. In: Indian Mushrooms (ed MC Nair). Kerala Agricultural University, Velenikkara, pp 13-24.

Atri NS, Kaur A, Kour H. 2005 - Wild mushrooms-collection and identification. In: Frontiers in Mushroom Biotechnology (eds RD Rai, RC Upadhyay, SR Sharma). NRCM Solan, India, pp 9-26.

Bhavani Devi S 1995 - Mushroom flora of Kerala. In: Advances in Hortriculture Vol. 13Mushrooms (eds KL Chadha, SR Sharma). Malhotra Publishing House, New Delhi, pp 277-316.

Bhide VP, Pande A, Sathe AV, Rad VG, Patwardan, PG. 1987 - Fungi of Maharashtra. Maharashtra Association for the Cultivation of Science. MACS Research Institute, Pune, India.

Bose SR 1920 - Records of Agaricaceae from Bengal. The journal of the Asiatic Society of Bengal $16,347-354$. 
Dhancholia S, Bhatt JC, Pant SK. 1991 - Studies of some Himalayan Agarics. Acta Botanica Indica 19(1), 104-109.

Ghosh RN, Pathak NC, Tiwari T. 1967 - Studies on Indian Agaricales. Indian Phytopathology 20, 237-242.

Holmgren PK, Keuken W (eds) 1974 - Index Herbariorum. Part I. The Herbaria of the World. Regnum Vegetabile 92, 1-397.

Kirk PF, Cannon PF, Minter DW, Stalpers JA. 2008 - Ainsworth and Bisby's 'Dictionary of Fungi' $\left(10^{\text {th }} \mathrm{Ed}\right)$. CABI Bioscience, CAB International, UK.

Kornerup A, Wanscher JH. 1978 - Methuen Handbook of Colour, $3^{\text {rd }}$ ed, Eyre Methuen, London.

Lakhanpal TN 1986 - Hallucinogenic mushrooms. In: Souvenir of Mushrooms, National Centre for Mushroom Research and Training, Solan.

Lakhanpal TN 1993 - The Himalayan Agaricales - Status of systematics. Mushoom Research 2(1), $1-10$.

Lakhanpal TN 1995 - Mushroom Flora of North West Himalayas. In: Advances in Horticulture Vol. 13- Mushrooms (eds KL Chadha, SR Sharma). Malhotra Publishing House, New Delhi, pp 351-373.

Manimohan PK, Thomas A, Nisha VS. 2007 - Agarics on elephant dung in Kerala State, India. Mycotaxon 99, 147-157.

Natarajan K, Raaman N. 1983 - South Indian Agaricales. Bibliotheca Mycologica 89, 1-203.

Natarajan K, Raaman N. 1984 - South Indian Agaricales. A preliminary study on some dark spored species. International Books and Periodicals Supply Services, New Delhi, pp 1-204.

Pathak NC, Ghosh RN. 1962 - Fungi of Uttar Pradesh. Bulletin of the National Botanic Gardens, No. 62, National Botanic Gardens, Lucknow, India.

Patil BD, Jadhav SW, Sathe AV. 1995 - Mushroom flora of Maharashtra. In: Advances in Hortriculture Vol. 13- Mushrooms (eds KL Chadha, SR Sharma). Malhotra Publishing House, New Delhi, pp 317-228.

Sarbhoy AK, Daniel J. 1981 - Fungi of India. CBS Publishing, New Delhi, India.

Sathe AV, Sasangan KC. 1977 - Agaricales from South West India-III. Biovigyanam 3, 119-121.

Stamets P 1996 - Psilocybin Mushrooms of the World. Ten Speed Press, Berkeley.

Vrinda KB, Pradeep CK, Mathew S, Abraham TK. 1999 - Agaricales from Western Ghats-VI. Indian Phytopathology 52(2), 198-200.

Watling R, Gregory NM. 1987 - British Fungus Flora-Agaric and Boleti 5. Strophariaceae and Coprinaceae. Royal Botanic Gardens, Edinburgh. 